\title{
Demand for Engineering Qualifications in the Transformation Period
}

\author{
M. V. Simonova ${ }^{1(\bowtie)}$, L. V. Sankova ${ }^{2}$, F. I. Mirzabalaeva ${ }^{3}$, \\ and E. V. Privorotskaya ${ }^{4}$ \\ ${ }^{1}$ Samara State University of Economics, Samara, Russia \\ m.simonova@mail.ru \\ ${ }^{2}$ Yuri Gagarin State Technical University of Saratov, Saratov, Russia \\ sankovalv@sstu.ru \\ ${ }^{3}$ Plekhanov Russian University of Economics, Moscow, Russia \\ faridamir@yandex.ru \\ ${ }^{4}$ Samara State Technical University, Samara, Russia \\ dmipriv@mail.ru
}

\begin{abstract}
The study analyzes the situation on the labor market in four regions of the Volga Federal District of the Russian Federation in the context of a professional group of engineering and technical specialties. The analysis was performed to identify the conformity of training volumes, the structure of employment by education, the structure and dynamics of active resumes and vacancies. The purpose of the research is to identify trends in demand for engineering qualifications in a strategic perspective and to overcome the consequences of the coronavirus pandemic. The authors revealed the tendency to increase and equalize the expenditures of regional budgets on education, and to reduce output in the studied group of specialties. The structure of supply and demand in labor markets of the Volga Federal District, which is characterized by a highly competitive situation among applicants and a decrease in job offers, is determined. The necessity of advanced training of engineering and technical specialists with basic digital skills is justified.
\end{abstract}

Keywords: Digital skills $\cdot$ Supply and demand in the labor market $\cdot$ Technical engineers $\cdot$ Transformation $\cdot$ Qualification

\section{Introduction}

The period of global transformations around the world leads to irreversible consequences in many sectors of the economy, destroys the structure of interconnections in the global economic system. There is a real prospect of mass unemployment, which was recently discussed, but in another aspect - it happens because of automation and robotization of production [9]. The imposition of these processes will have consequences for the entire labor market, including for the specialized labor market oriented to industry [10].

During and after the crisis, it becomes obvious that many formats of the digital economy will not be able to continue to develop or die, such as a bloated financial 
sector, many types of services built on entertainment and consumer industries. The sphere of real material production of necessities, communications, global infrastructure projects aimed at the domestic consumer in the country will come to the fore. To realize such a strategic perspective, human and labor resources are required that are professionally oriented to fulfill technical tasks in the first place. Basic technical skills become strategic capital, which is not subject to devaluation and has a reproducible base on which new technologies and systems can be created [7]. In this situation, the technical orientation of the labor potential in a particular territory, the regional profile of the correspondence of the labor market and the education system in engineering specialties will be of decisive importance [6].

Consumption, as it has evolved over the past decades, will have to undergo significant changes related to both the forced restriction of consumption and the restructuring of the system of economic relations. In this regard, the structure of the labor market will change significantly. One of the main segments of labor markets in the coming years will most likely be industrial production, by which we mean the production of real consumption products based on digitalization of all processes, these are precisely technical, engineering and economic competencies. One of the trends identified in scientific research in recent years has been the reduction of employment in the sphere of material production and the increase in the services sector, while industrial production has moved into the category of fully automated and almost eliminating human presence [5]. The onset of the global economic crisis provoked by the coronavirus can dramatically change both the structure of the global economy and, accordingly, the labor market. In this situation, industrial production, initiated by regional and national interests, can become the driver that will allow bringing the scale of employment to optimal values. In addition, automation and robotization of routine operations can reduce jobs in the production process, but at the same time creates entire segments of new jobs associated with servicing the technological cycle, designing, programming and organizing labor according to the design principle [1]. In this situation, the basic engineering skills acquired in the vocational training system and the adaptive development and mentoring system at the enterprise are priorities.

\section{Methodology}

Employment in the region is determined by the development of traditional or priority sectors of decisive national economic importance [15]. Most often, workers live in the region where the production is located. Therefore, the development of the labor potential of the production location is crucial for commercial success of the enterprise. As an example, we consider local relationships in neighboring regions of the Federal District; these are the Samara region, Republic of Tatarstan, Saratov and Ulyanovsk regions. For the analysis, we selected indicators of the education system, demand and supply on the labor market, statistics on employment and unemployment, as well as data presented on one of the most popular online work resource [11].

The indicated regions are in the Volga Federal District. They are comparable in size and population, they are in the same climatic zone near each other and are adjacent to the most important waterway of Russia - the Volga River. However, the regions differ 
in economic and labor potential, which is characterized, inter alia, by quantitative indicators of the system of professional and higher education. When assessing the region's labor potential by educational characteristics, both quantitative and qualitative indicators are important, for which, in our analysis, the following were taken: the number of organizations and graduates of higher and secondary specialized education in the region, the share of unemployed in the total number of employees, the share of employees with vocational education in the total number of employees and the growth rate of expenditures of the regional budget on education. It should be borne in mind that the costs of local budgets on education have a limitation, since only general and secondary vocational education is financed from them, higher education is provided by the federal budget. The most relevant and dynamic information about vacancies and job seekers is job sites, which have become the most accessible and sought-after employment tool that responds to changes in the situation in almost real time. A joint analysis of statistics and data on the number and structure of resumes and vacancies can show the state of the specialized labor market oriented to industry.

\section{Results}

The share of specialists with higher and secondary vocational education in the total number of employed and unemployed shows demand for qualified specialists and the possibility of finding a person with vocational training. An assessment of the general situation in regions with the training of specialists can be carried out by graduation dynamics of young specialists with vocational training. For the possibility of comparing data, we took expenditures on education in relative units, taking 2009 as the base value from which we calculated the annual growth rate. However, a comparison of absolute indicators of expenditures of regional budgets is also significant. The comparison was carried out according to the following indicators, indicated in Fig. 1 for each region:

1. Growth rate of regional budget expenditures on education, $\%$.

2. Number of organizations of higher and secondary vocational education, units.

3. Number of graduates of higher and secondary vocational educational organizations, thousand people.

4. Unemployed population with higher and secondary vocational education, in $\%$ of the total number of employees.

5. Employed population with higher and secondary vocational education, in $\%$ of the total number of employees.

The most significant growth rate of regional budget spending on education is observed in the Saratov and Ulyanovsk regions. However, in absolute terms, the cost of education in these regions remains almost two times lower than in the Samara region and the Republic of Tatarstan. This largely depends on the development of the economy and budget revenues in the whole region, however, we can note the tendency to equalize differences in the cost of education in neighboring regions.

The reduction in the number of educational organizations training workers and specialists, as well as in the number of graduates in all the regions under consideration 
is indicative, which can only partially be explained by the decline in the demographic wave. An alarming trend may also be associated with the outflow of promising youth in capital regions. This requires additional measures to develop regional education systems and create attractive jobs. An increase in the share of specialists with education in the total number of employees is observed in the Republic of Tatarstan and the Samara region, which shows higher qualification requirements. Accordingly, we can assume that the economic structure of these regions allows us to create more efficient jobs. At the same time, it is also necessary to note an increase in the share of specialists with education among the unemployed, in contrast to the Saratov and Ulyanovsk regions. The situation may be characterized by trends in economic digitalization, when the creation of a new type of jobs increases the requirements for education and qualifications, unskilled labor remains in demand due to low profitability of automation of many processes, and staff with average qualifications are put out of jobs. Thus, development trends of educational components of regions' labor potential can characterize the economic situation and the directions to develop labor markets.

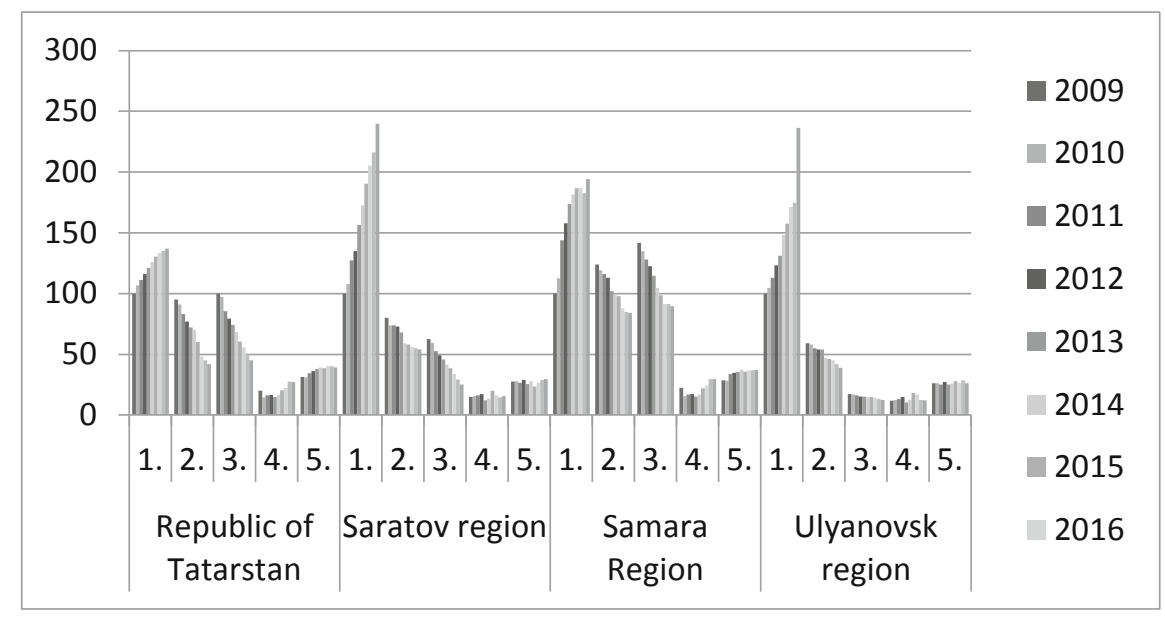

Fig. 1. Analysis of educational components of regions' labor potential of the Volga Federal District (Source: authors).

The growth of qualification requirements is especially noticeable in high-tech sectors of the economy, in which there are high requirements for technical education and special engineering skills, the development of which occurs when receiving basic education in undergraduate, specialty and master's programs. Using the example of the Samara region, we analyzed the region's provision with graduates of several common technical training areas - Heat and Power Engineering, Electric Power and Electrical Engineering, Power Engineering, Construction, as these specialties are the most popular in the region's labor market. To assess the state and identify the trend, we calculated the share of the number of graduates in the total number of graduates of the Samara region and compared with the share of graduates in this specialty in the Russian Federation (Table 1). 
Table 1. The proportion of graduates of technical specialties in the Samara region

\begin{tabular}{l|l|l|l|l}
\hline Name of training (specialty) & 2015 & 2017 & 2018 & 2019 \\
\hline Heat power engineering and heat engineering, people & 58 & 116 & 143 & 112 \\
\hline Power industry and electrical engineering, people & 288 & 569 & 529 & 270 \\
\hline Power engineering, people & 31 & 93 & 93 & 62 \\
\hline Construction, people & 383 & 835 & 825 & 573 \\
\hline Number of graduates of the Samara region in 4 training programs, people & 760 & 1613 & 1590 & 1017 \\
\hline $\begin{array}{l}\text { Number of graduates of the Samara region in all training programs, } \\
\text { people }\end{array}$ & 11913 & 19337 & 19596 & 19743 \\
\hline $\begin{array}{l}\text { Share of graduates of the Samara region in 4 training programs of the total } \\
\text { number of graduates of the Samara region, \% }\end{array}$ & 6,4 & 8,3 & 8,1 & 5,2 \\
\hline $\begin{array}{l}\text { Number of graduates of the Russian Federation in 4 training programs, } \\
\text { people }\end{array}$ & 36855 & 55810 & 53270 & 54855 \\
\hline $\begin{array}{l}\text { Share of graduates of the Samara region in 4 training programs from the } \\
\text { total number of graduates of the Russian Federation, \% }\end{array}$ & 2,1 & 2,9 & 3 & 1,9 \\
\hline
\end{tabular}

(Source: authors).

The number of graduates was calculated as the sum of graduates in 3 levels of higher education - undergraduate, specialty, master's degree. In 2019, there was a significant drop in the number of graduates in all the areas of training programs considered, which is characterized by a decrease in both absolute indicators and the share in the total number of graduates. At the same time, in 2017-18 there was an increase in all specialties, after which the number of graduates decreased to a value less than it was in 2015, with a steady increase in the total number of graduates of higher education in the Samara region and in the Russian Federation. The share of graduates of the studied areas in the Samara region is almost three times higher than the share of all graduates in the country, since energy and construction are one of the priority sectors of the Samara region and the education system must correspond to the structure of the local economy. The number of graduates in the Samara region and in the Russian Federation is growing quite proportionally to each other.

The entry of new specialists into the labor market is accompanied by redistribution of labor resources in accordance with economic, professional and personal needs that characterize supply and demand in a territory. Crisis situations are characterized by instantaneous dissonance in the number of resumes and vacancies in the labor market. Reliable distributed data can be estimated at the end of the year, but even now you can evaluate the dynamics and structure of supply on the labor market, which cannot change as quickly as the number of vacancies. Employment in the Russian Federation is regulated by the state to a rather high degree, as shown by previous crises of 2008 and 2014. We analyzed the number of resumes and vacancies in the labor market of the regions of the Volga Federal District to identify labor market conditions and determine employment trends in the industrial sector. The number of resumes and vacancies was estimated over several periods - the total number of active resumes and vacancies not currently filled, including the number of resumes and vacancies posted within the last week (as of 04.25.2020), within the last month, within the last year. Since the professional group with the qualification of Engineer is quite extensive, we compared the number of resumes for all resumes with the mention of the word Engineer in the title and allocated a group of resumes specializing in Industry and Construction (Table 2). 


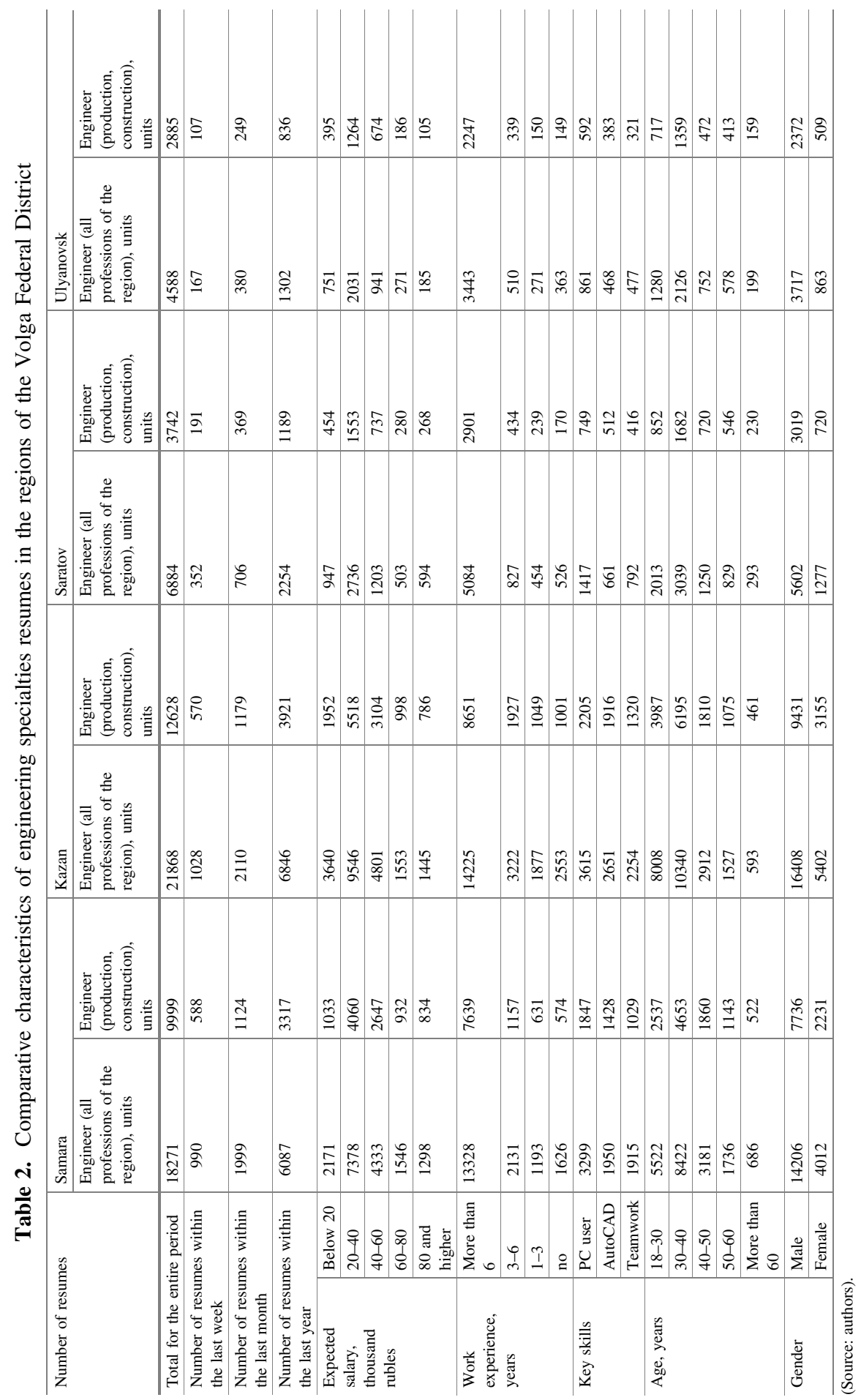


Quantitative characteristics for all periods are comparable and allow dividing resumes into two groups according to quantitative indicators - Samara and Kazan in one group and Saratov and Ulyanovsk in another, in which the number of resumes differs by 3-4 times. Great attractiveness is justified by a significant difference in salary expectations of applicants. The largest number of applicants in all four regions expects to have salary in the range of 20-40 thousand rubles, which shows approximately the same standard of living in the studied regions, but the probability of finding a qualified specialist from employers in Kazan and Samara is much higher. Analysis of the structure of applicants by age shows that the most dynamic age group, prone to changing professional and official position, is a group of 30-40-year-old specialists who have received education, professional experience and have a desire to find more decent working conditions. As age increases, the number of resumes decreases and after 40 years the largest number of resumes, compared to other cities, is posted in Samara, and Kazan is the leader in the number of resumes under the age of 40 years. In general, for all the cities studied, the most active part of the workforce is the age category up to 40 years. The key skills for engineers are the ability to use a computer and specialized programs, the less important is the ability to work in a team, which is determined by the nature of engineering work.

The number of vacancies for engineering positions decreased in all the studied regions (Fig. 2).

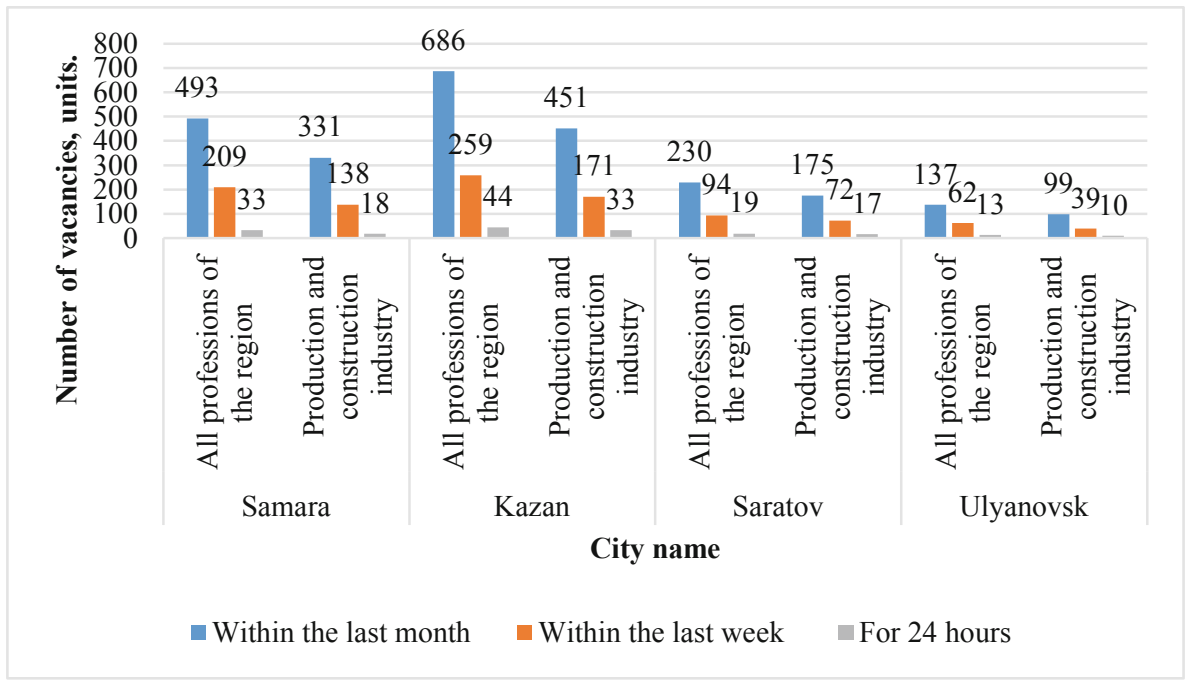

Fig. 2. The dynamics of the number of vacancies posted in the regions of the Federal Volga District (Source: authors).

The increase in vacancies within the last month shows a negative trend, the largest decrease in the number of posted vacancies occurred in Ulyanovsk by $6 \%$, only in Saratov there is a slight increase of $1 \%$. At the same time, in all cities under 
consideration there is an increase in the number of resumes by 5-13\%, the largest in Kazan. The labor market remains highly competitive, 7-9 people per vacancy, this situation in the short term will tend to increase until the end of the pandemic. When implementing the strategy for domestic consumption and national investment projects, the situation may change in the direction of increasing the number of vacancies, competition in the labor market will decrease, and to meet the needs of the new economy in qualified personnel, their preparation should begin at a faster pace.

Salary offers far exceed the expectations of applicants, qualifications and areas of responsibility are of great importance (Fig. 3).

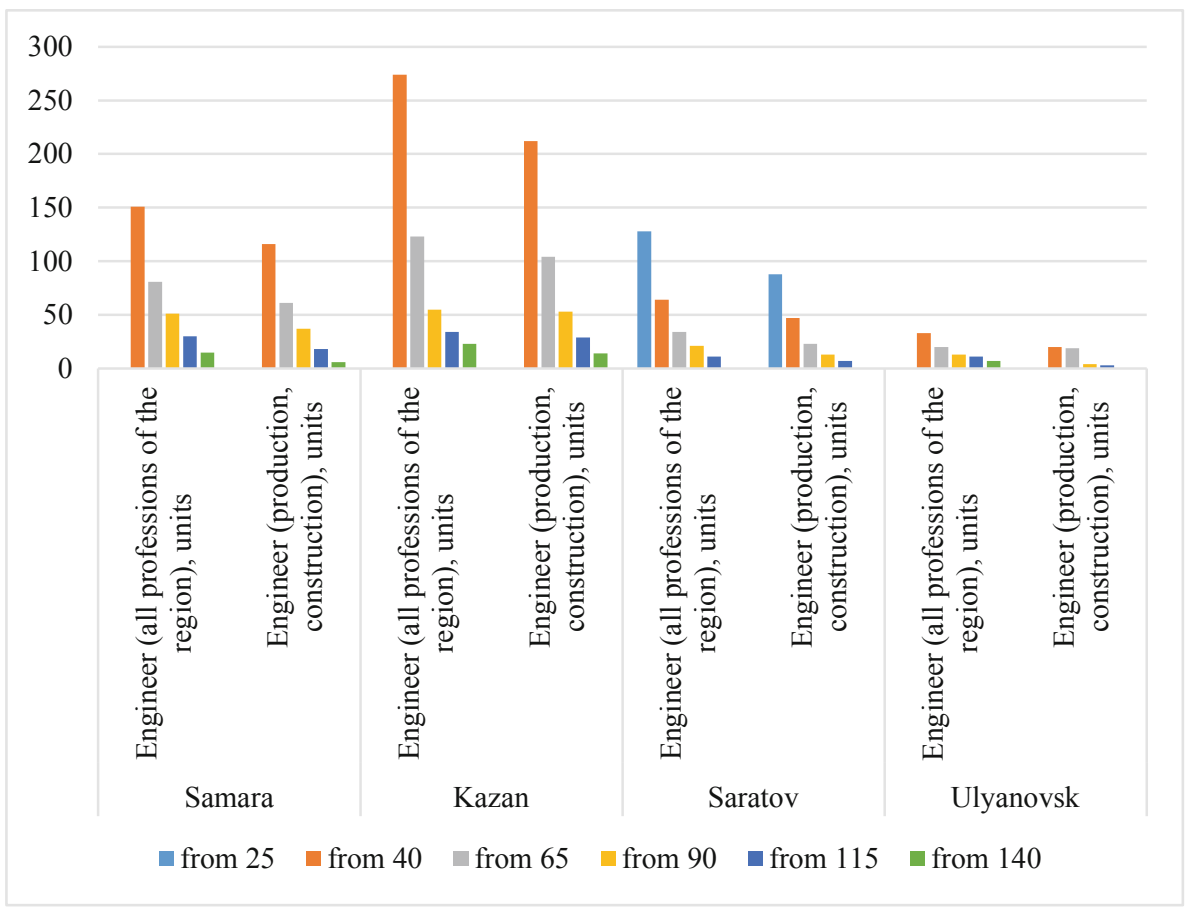

Fig. 3. Salary offers in the posted vacancies of the regions of the Federal Volga District (Source: authors).

There is a significant difference in salaries offered in vacancies in different cities. In Samara, Kazan and Ulyanovsk, there are no vacancies with salary below 25 thousand rubles, such a salary is offered only in Saratov. In Samara and Kazan, the largest number of vacancies with salary of 40-65 thousand rubles, in Saratov from 25 to 40 thousand rubles, in Ulyanovsk with a small total number of vacancies, the proposed level of salary is in the range of 40-65 thousand rubles. 


\section{Discussion}

The relationship between the requirements for applicants, the proposed remuneration and qualifications of applicants has been a debated area of science for many years [8]. Recent years of discussion have been around the impact of competence and qualifications on the level of remuneration, the ratio of "soft" and "hard" skills to form a successful career [3]. Many researchers, in our opinion, unreasonably overestimate the importance of "soft" skills, often to the detriment of basic, fundamental knowledge.

In our opinion, this specificity is more characteristic for leadership, managerial positions, which are crucial for leadership qualities [12]. Our studies show the priority of technical and informational knowledge, which is given by both job seekers in resumes and employers in vacancies. The qualification characteristics and level of job positions are of great importance, when personal qualities practically do not matter in low-skilled positions [4]. Interregional labor market research conducted in our country confirms the trends of a stable technical and technological stratum of specialists with both technical and digital skills in many regions [13].

In recent years, qualification requirements have grown across the entire spectrum of engineering and technical jobs, often in vacancies one can note clearly overstated requirements that do not correspond to the regional labor market. But this situation encourages applicants to increase their competence and to increase competitiveness in the labor market [14]. This primarily concerns the skills associated with the use of artificial intelligence [2]. Such skills become basic for all technical specialists.

\section{Conclusion}

Studies have shown general trends in engineering qualifications in neighboring regions with a significant difference in absolute terms. The training in the selected group of specialties is carried out in enough volume, but the reduction in output is worrying when the labor market has long-term demand for advanced engineering, technical and digital skills.

The authors analyzed the number of graduates in the group of training areas corresponding to the most demanded qualifications in the regional labor market. They have noted the equalization of regional spending on the formation of local budgets, a gradual increase in the share of employees with vocational education. Based on the identified trend of reducing the number of graduates of the required specialties, it is necessary to develop targeted training of young specialists in educational organizations.

The analysis of the correspondence of the number and structure of resumes and vacancies showed that the labor market in the studied regions of the Federal Volga District is highly competitive, with a significant advantage in favor of the interests of employers and unsatisfied demand of applicants in the most developed regions of the Samara region and the Republic of Tatarstan. The labor market of the Saratov and Ulyanovsk regions is more balanced, although less attractive to applicants.

An alarming situation is when there has been a decrease in the number of vacancies in economically more developed regions within the last month, due to the epidemiological situation. In implementing the strategic goals of the country's economic growth, 
based on national projects and the development of domestic consumption, we need accelerated growth in the training of engineering and technical specialists with basic digital skills.

\section{References}

1. Albuquerque, P.H.M., Saavedra, C.A.P.B., de Morais, R.L., Peng, Y.: The robot from Ipanema goes working: estimating the probability of jobs automation in Brazil. Latin Am. Bus. Rev. 20(3), 227-248 (2019)

2. Alekseeva, L., Azar, J., Gine, M., Samila, S., Taska, B.: The demand for AI skills in the labor market. SSRN Working Paper (2019). https://papers.ssrn.com/sol3/papers.cfm? abstract_id=3526045. Accessed 29 Apr 2020

3. Alpaydın, Y.: Identifying higher-education level skill needs in labor markets: the main tools usable for Turkey. Kuram ve Uygulamada Egitim Bilimleri 15(4), 945-967 (2015)

4. Beblavý, M., Mýtna Kureková, L., Haita, C.: The surprisingly exclusive nature of mediumand low-skilled jobs: evidence from a Slovak job portal. Pers. Rev. 45(2), 255-273 (2016)

5. Börner, K., Scrivner, O., Gallant, M., Ma, S., Liu, X., Chewning, K., Evans, J.A.: Skill discrepancies between research, education, and jobs reveal the critical need to supply soft skills for the data economy. Proc. Natl. Acad. Sci. U.S.A. 115(50), 12630-12637 (2018)

6. Büth, L., Blume, S., Posselt, G., Herrmann, C.: Training concept for and with digitalization in learning factories: an energy efficiency training case. Proc. Manuf. 23, 171-176 (2018)

7. Darabi, H., Karim, F.S.M., Harford, S.T., Douzali, E., Nelson, P.C.: Detecting current job market skills and requirements through text mining (2018). https://www.semanticscholar. org/paper/Detecting-current-job-market-skills-and-through-Darabi-Karim/ 10bd61ee3b72c8003b5f6446e865c9a958c424aa. Accessed 29 Apr 2020

8. Karmaeva, N.: The Oxford handbook of skills and training. J. Econ. Sociol. 20(4), 114-125 (2019)

9. Maresova, P., Soukal, I., Svobodova, L., Hedvicakova, M., Javanmardi, E., Selamat, A., Krejcar, O.: Consequences of industry 4.0 in business and economics. Economies 6(3), 46 (2018)

10. Reinhold, M., Thomsen, S.: The changing situation of labor market entrants in Germany. J. Labour Mark. Res. 50(1), 161-174 (2017)

11. Rosstat: Socio-economic indicators (2019). http://gks.ru/storage/mediabank/Region_Pokaz_ 2019.pdf. Accessed 29 Apr 2020

12. Sopegina, V.T., Chapaev, N.K., Simonova, M.V.: Integration of pedagogical and technological knowledge in forming meta-competencies of a modern worker. Int. J. Environ. Sci. Educ. 11(15), 7836-7846 (2016)

13. Simonova, M.V., Sankova, L.V., Mirzabalaeva, F.I., Shchipanova, D.Y., Dorozhkin, V.E.: Assessment problems and ensuring of decent work in the Russian regions. Int. J. Environ. Sci. Educ. 11(15), 7608-7626 (2016)

14. $\mathrm{Vu}$ Anh, T.L., Le Quoc, T.: Development orientation for higher education training programme of mechanical engineering in industrial revolution 4.0: a perspective in Vietnam. J. Mech. Eng. Res. Dev. 42(1), 71-73 (2019)

15. Yildiz, F.: The role of education in the participation of Turks living in Europe in labor Markets. Proc. Soc. Behav. Sci. 186, 1179-1187 (2015) 